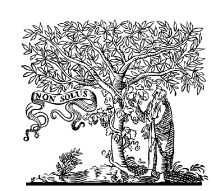

ELSEVIER

\title{
EDITORIAL
}

\section{Letter from the Editor}

Dear Fellows of the ACCWS,

The New Year brings many exciting events that the College will offer to our growing membership.

First I am very pleased to confirm that the manuscripts that were published in the College's Journal were retrospectively posted on PubMed and PubMed Central. This will give the authors who contributed to the Journal the credit and visibility that they deserve.

We are continuing our discussions with colleagues in Europe regarding the merger of the College Journal with the Wound Medicine Journal. We will keep you posted with the progress.

Our relationship with Kindred Health Network will be strengthened by the initiation of new educational programs throughout the country. An expanded version of the College's signature B2B course will be taught annually in many Kindred facilities.

We are happy to announce the College's "Fourth Annual Symposium on Advancing the Standards in Wound Care and Hyperbaric Medicine." The new

collaboration between the American College of Clinical Wound Specialists, Wright State University Boonshoft School of Medicine and the University of Toledo will be held in November 7, 2014. The collaboration it will take the already superb Symposium to a new level of excellence. This regional collaboration will be the prelude to the 2015 first national Symposium planned to be held in Chicago. More details will be announced at a later time. Your continued support and commitment to the College is essential to the success of this venture. Our headquarters will keep you posted with the anticipated date of the meeting.

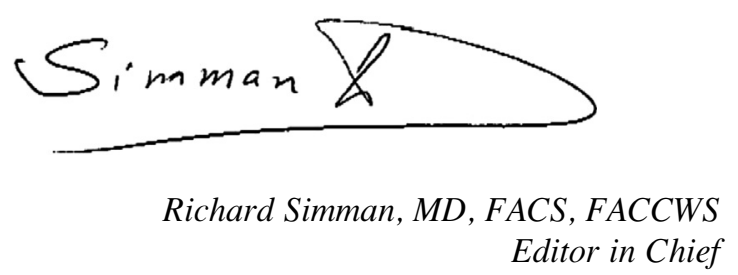

